\title{
Methods to Assess the Direct Interaction of C. Jejuni With Mucins
}

\author{
Julie Ann Naughton \\ Technological University Dublin, julieann.naughton@tudublin.ie \\ Marguerite Clyne \\ University College Dublin \\ Gina Duggan \\ University College Dublin, gina.duggan@tudublin.ie
}

See next page for additional authors

Follow this and additional works at: https://arrow.tudublin.ie/scschbiobk

Part of the Bacteriology Commons, and the Biochemistry, Biophysics, and Structural Biology Commons

\section{Recommended Citation}

Naughton, J., Clyne, M., Duggan, G. \& Burke, B. (2017). Methods to assess the direct interaction of C. jejuni with mucins. In Methods in Molecular Biology,vol. 1512, pp. 107-115. doi:10.1007/978-1-4939-6536-6_10

This Book Chapter is brought to you for free and open access by the School of Biological Sciences at ARROW@TU Dublin. It has been accepted for inclusion in Books/Book chapters by an authorized administrator of ARROW@TU Dublin. For more information, please contact arrow.admin@tudublin.ie, aisling.coyne@tudublin.ie, gerard.connolly@tudublin.ie. Funder: Science Foundation Ireland

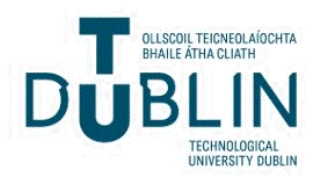




\section{Authors}

Julie Ann Naughton, Marguerite Clyne, Gina Duggan, and Billy Bourke

This book chapter is available at ARROW@TU Dublin: https://arrow.tudublin.ie/scschbiobk/4 


\title{
Methods to assess the direct interaction of $C$. jejuni with mucins.
}

\author{
Marguerite Clyne ${ }^{1}$, Gina Duggan ${ }^{1}$, Julie Naughton², Billy Bourke ${ }^{1,3}$ \\ ${ }^{1}$ Conway Institute, School of Medicine, University College Dublin, ${ }^{2}$ School of Biological \\ Sciences, DIT Kevin Street, Dublin 1,3National children's Research Center, Our Lady's \\ Children's Hospital Crumlin Dublin, Ireland.
}

Acknowledgements:

This work was supported by a grant from Science Foundation Ireland (08/SRC/B1393)

Key Words:

Campylobacter jejuni, mucus, mucin array, SDS PAGE, Slot blot, PVDF. 


\section{Summary}

Studies of the interaction of bacteria with mucus secreting cells can be complemented at a more mechanistic level by exploring the interaction of bacteria with purified mucins. Here we describe a far western blotting approach to show how $C$. jejuni proteins separated by SDS PAGE and transferred to a membrane or slot blotted directly onto a membrane can be probed biotinylated mucin. In addition we describe the use of novel mucin microarrays to assess bacterial interactions with mucins in a high throughput manner.

\section{Introduction}

There is an increasing body of evidence that components of the mucus gel layer plays an important role in determining the outcome of $C$. jejuni infection. Whereas human mucus has been shown to promote colonisation of cell lines (1) and virulence (2) in $C$. jejuni, chicken mucus has been shown to attenuate these characteristics $(3,4)$. Mucins and the biochemical makeup of the mucus layer have also been shown to play an important role in mucosal defense against $C$. jejuni infection in vivo (5-7).

\subsection{Probing of $\mathrm{C}$. jejuni proteins with biotin labelled mucin.}

C. jejuni whole cell lysates can be either slot blotted directly to PVDF or separated by polyacrylamide gel electrophoresis and transferred electrophoretically to a polyvinylidene difluoride (PVDF) membrane. Putative mucin binding proteins can be detected by probing with labeled purified mucins (Figure 1). Biotin is a suitable label due to its small size, high affinity and resistance to heat, $\mathrm{pH}$ and proteolysis. Slot blots are a simplified version of traditional blotting methods in that biomolecules of interest are not separated by electrophoresis but applied directly to a PVDF membrane. This method allows fast detection of the presence of a particular ligand but not the mass or number of reactive targets in a sample.

\subsection{Probing of mucin printed on an array slide with $\mathrm{C}$. jejuni}

Mucin purification is a tedious process, which often does not yield sufficient amounts of target protein. Differences in glycosylation between individuals presents further issues, 
preventing pooling of samples in order to produce sufficient yields. A novel highthroughput approach to investigating the interaction of bacteria with mucins is the use of mucin microarrays (1). Mucins isolated from any tissue source can be immobilised onto microarray slides (8). In the arrays that we use there are eight identical subarrays per slide and each mucin is printed in replicates of six per subarray.

\section{Materials}

\subsection{SDS-Polyacrylamide gel components}

1. Resolving Gel Buffer: $1.5 \mathrm{M}$ Tris- $-\mathrm{HCl}$ buffer, $\mathrm{pH} 8.8$

2. Stacking Gel Buffer: $0.5 \mathrm{M}$ Tris- $\mathrm{HCl}$ buffer, $\mathrm{pH} 6.8$

3. $30 \%$ acrylamide/Bis solution (29.2:0.8 acrylamide:Bis).

4. Ammonium persulfate: $10 \%(\mathrm{wt} / \mathrm{vol})$ solution in water.

5. $\mathrm{N}, \mathrm{N}, \mathrm{N}, \mathrm{N}^{\prime}$-tetramethyl-ethylenediamine (TEMED). Store at $4^{\circ} \mathrm{C}$.

6. Distilled $\mathrm{H}_{2} \mathrm{O}$.

7. $10 \%$ Sodium dodecyl sulfate (SDS) (wt/vol) in water. Store at room temperature.

8. 6x SDS PAGE sample loading buffer ( $375 \mathrm{mM}$ Tris $\mathrm{HCl} \mathrm{pH} \mathrm{6.8,} \mathrm{10 \%} \mathrm{SDS} \mathrm{(wt/vol),}$ $50 \%$ glycerol ( $\mathrm{vol} / \mathrm{vol}$ ), $10 \%$-mercaptoethanol (vol/vol), $0.03 \%$ bromophenol blue (wt/vol) in $\mathrm{dH}_{2} \mathrm{O}$.

9. $2 \times$ SDS PAGE sample loading buffer: mix 1 part 6 X SDS PAGE sample loading buffer with 2 parts $\mathrm{dH}_{2} \mathrm{O}$.

\subsection{Electrophoretic Transfer components}

1. PVDF membrane cut slightly larger than gel size, notched in one corner.

2. Six sheets of Whatman paper per gel to be transferred cut to a size slightly larger than the gel.

3. Galileo mini twin gel unit (catalog \#85-1010) or equivalent

4. Galileo bioscience glass plates (catalog \#85-1010-G10) or equivalent

5. Methanol

6. Electroblotting tank, cassette, scotchbrite pads, Voltage power pack.

7. Coomassie Blue Stain R250 
8. 5X Transfer Buffer: $0.025 \mathrm{M}$ Tris, $0.192 \mathrm{M}$ glycine and $20 \%$ methanol

9. $1 X$ Transfer Buffer: 1 part $5 X$ transfer buffer, 3 parts $\mathrm{dH}_{2} \mathrm{O}$ and 1 part methanol. Store at $4^{\circ} \mathrm{C}$.

10. $10 X$ Tris buffered saline (10X TBS): $1.5 \mathrm{M} \mathrm{NaCl}, 0.1 \mathrm{M}$ Tris- $\mathrm{HCl}, \mathrm{pH} 7.4$

11. 1 X TBS: 1 part $10 X$ TBS and 9 parts $\mathrm{dH}_{2} \mathrm{O}$

12. Wash buffer (TBST): $1 X$ TBS containing $0.05 \%$ (vol/vol) Tween-20

\subsection{Mucin overlay and Slot Blot components}

1. PVDF membrane

2. Methanol

3. Slot Blot Manifold

4. 10X Tris buffered saline (10X TBS): $1.5 \mathrm{M} \mathrm{NaCl}, 0.1 \mathrm{M}$ Tris- $\mathrm{HCl}, \mathrm{pH} 7.4$

5. 1X TBS: 1 part $10 X$ TBS and 9 parts $\mathrm{dH} 2 \mathrm{O}$

6. TBST: $1 X$ TBS containing $0.05 \%$ Tween-20

7. Sterile Dulbecco 'A' Phosphate buffered saline $\mathrm{pH} 7.3$ (PBS)

8. EZ link sulfo-NHS Biotin

9. Purified mucin resuspended in $\mathrm{dH}_{2} \mathrm{O}$

10. Dialysis cassette with a molecular weight cut off of approx. 20,000 Da

11. 1 L beaker

$12.3 \%$ gelatin in $1 \mathrm{X}$ TBS

13. Streptavidin-peroxidase conjugate $(1: 50,000)$ in $3 \%$ gelatin in $1 X$ TBS

14.22 gauge needle

15. Plastic bag

16. Heat sealer

17. Clingfilm

18. SuperSignal West Pico Chemiluminescent Substrate (Thermo Scientific)

19. Plastic separator

20. Heat block

\subsection{Incubation of mucin arrays with $\mathrm{C}$. jejuni}


1. Log phase liquid culture of $C$. jejuni grown as described in chapter $\mathrm{X}$, section 3.1, steps 1-3.

2. $500 \mu \mathrm{M}$ Syto82 (Life Technologies) (Note 1)

3. Sterile Dulbecco 'A' Phosphate buffered saline pH 7.3 (PBS)

4. Low salt Tris-buffered saline (LS-TBS): $20 \mathrm{mM}$ Tris, $100 \mathrm{mM} \mathrm{NaCl}, 1 \mathrm{mM} \mathrm{CaCl}_{2}, 1$ $\mathrm{mM} \mathrm{MgCl} 2, \mathrm{pH} 7.2$

5. LS-TBST: LS-TBS supplemented with $0.05 \%$ Tween 20

6. 8-well gasket slide and incubation cassette system (Agilent Technologies)

7. Stainless steel slide rack

8. Glass staining dishes

9. Mucin microarrays

10. Log phase culture of $C$. jejuni

11. TRITC-labelled lectins eg. Ulex europaeus agglutinin I (UEA-I), Artocarpus integrifolia agglutinin (AIA) (EY Laboratories, Inc., San Mateo, CA, USA)

\section{Method}

\subsection{Sodium dodecyl sulfate Polyacrylamide gel Electrophoresis}

1. Mix $2.5 \mathrm{~mL}$ of resolving gel buffer, $3.33 \mathrm{~mL}$ of $30 \%$ acrylamide, $4 \mathrm{~mL}$ of water and $100 \mu \mathrm{L}$ of $10 \%$ SDS in a universal tube. Add $100 \mu \mathrm{L}$ of $10 \%$ ammonium persulfate, and $4 \mu \mathrm{L}$ of TEMED, mix and cast gel immediately within a $10 \mathrm{~cm} \times 10 \mathrm{~cm} \times 1.5 \mathrm{~mm}$ gel cassette (see Note 2). Allow space for the stacking gel and gently add approx. 30 $\mu \mathrm{L}$ isopropanol on top of the poured gel to remove air bubbles. Allow gel to set.

2. Prepare the stacking gel by mixing $0.38 \mathrm{~mL}$ of stacking gel buffer, $0.5 \mathrm{~mL}$ of $30 \%$ acrylamide, $2.1 \mathrm{~mL}$ water and $30 \mu \mathrm{L}$ of $10 \%$ SDS in a universal tube. Add $30 \mu \mathrm{L}$ of $10 \%$ ammonium persulfate and $3 \mu \mathrm{L}$ of TEMED. Remove the isopropanol from the top of the set resolving gel (see Note 3) and pour the stacking gel. Insert a 10-well gel comb immediately without introducing air bubbles and allow to set.

\subsection{Electrophoretic transfer}

1. Fill the electroblotting tank with $1 \mathrm{X}$ transfer buffer (See Note 4).
Commented [P1]: Chapter entitled Assays to study the interaction of Campylobacter jejuni with the mucosal surface.

Commented [A2]: Acronym changed to avoid confusion with TBS in other sections.

All references to TBS in this section have been changed to LS-TBS for clarity (ensure this is correct). If TBS should be used, please add TBS as a component in the materials section.

Commented [A3]: Acronym changed to avoid confusion with TBST in other sections.

All references to TBST in this section have been changed to LSTBST for clarity (ensure this is correct). If TBST is correct, please add TBS as a component in the material section. 
2. Wet the PVDF membrane for a few seconds in methanol (See Note 5).

3. Pre-soak Whatman paper in some transfer buffer.

4. Using a plastic separator, carefully remove the gel from the electrophoresis plates, cut the gel if necessary, notch the bottom right hand corner and place briefly in a tray filled with transfer buffer.

5. Open the cassette containing the gel and place three pre-soaked Whatman papers on one side of the apparatus on top of the Scotch brite. Place the gel on top of the Whatman paper and cover with the PVDF membrane, lining up the notches. Place the additional three Whatman papers on top and roll a $50 \mathrm{~mL}$ tube over the stack to eliminate any air bubbles.

6. Close the cassette and place it in the tank facing the PVDF membrane towards the positive electrode (red).

7. Transfer at $100 \mathrm{~V}$ for $1 \mathrm{~h} 30$ mins or at $15 \mathrm{~V}$ overnight at $4^{\circ} \mathrm{C}$.

\subsection{Mucin overlay}

All procedures are carried out at room temperature unless otherwise stated.

1. Resuspend the purified mucin $(0.1 \mathrm{mg} / \mathrm{mL}$ to $0.25 \mathrm{mg} / \mathrm{mL})$ in $\mathrm{dH}_{2} \mathrm{O}$ and biotinylate according to the manufacturers instructions (EZ-Link sulfo-N-hydroxysuccinimide biotinylation kit, (Pierce) (see Note 6). To remove excess biotin, transfer the mucin via a 22 gauge needle to a dialysis cassette with a molecular weight cut off of approx. $20,000 \mathrm{Da}$ and dialyze the sample in $1 \mathrm{~L}$ of $1 \times \mathrm{PBS}$ overnight at $4^{\circ} \mathrm{C}$.

2. C. jejuni whole cell lysates may be slot blotted directly onto the PVDF membrane or separated by electrophoresis on $10 \%$ polyacrylamide minigels and transferred to PVDF membranes for $1 \mathrm{~h} 30 \mathrm{~min}$ in a wet blotter (Bio-Rad, Hercules, CA) at $100 \mathrm{~V}$ (see Note 7).

3. Following transfer, block the PVDF membrane in $3 \%$ gelatin in 1X TBS overnight at $30^{\circ} \mathrm{C}$ at $50 \mathrm{rpm}$ in a shaking incubator (see Note 8).

4. Wash the membrane in TBST (see Note 9) and incubate with $1 \mathrm{~mL}$ biotinylated mucin overnight at room temperature. Retain the mucin for reuse (see Note 10) and wash the membrane three times for 10 min with TBST.

5. Incubate with streptavidin-peroxidase conjugate for $1 \mathrm{~h}$ at $37^{\circ} \mathrm{C}$ at $50 \mathrm{rpm}$. 
6. Wash the membrane three times for 20 min TBST (see Note 11).

7. Mucin-binding proteins may be detected by enhanced chemiluminescence. Remove the PVDF membrane from the wash buffer and place in a gel imaging viewer. Mix equal parts of SuperSignal West Pico Chemiluminescent Substrate (ECL substrate) and pipette directly onto the membrane. A dark exposure time ranging from 30 seconds to 5 minutes is recommended (see Note 12).

\section{4 Slot blot}

1. Assemble the slot blot apparatus, removing the upper slot module. Attach a vacuum to the vacuum chamber.

2. Cut a piece of PVDF membrane to the size and shape of the lower slot module.

3. Flood the lower slot module with $1 X$ TBS. Wet the PVDF membrane for a few seconds in methanol and place in the manifold, ensuring there are no air bubbles present.

4. Place the upper slot module on top of the PVDF membrane and seal tightly.

5. Dilute each sample to be slot blotted in approx. $50 \mu \mathrm{L} 1 \mathrm{X}$ TBS and apply to slot. Apply vacuum for approx. 60 seconds or until the entire sample has been pulled through.

6. Remove the membrane from manifold and follow instructions from step 3 of the mucin overlay procedure as above (section 3.3, steps 3 to 7 ).

\subsection{Incubation of C. jejuni with mucin microarrays}

1. Dilute down $C$. jejuni to an $O . D_{600}$ of 0.2 from the log-phase culture.

2. Pellet the bacteria by centrifugation at $6,500 \times g$ for 5 minutes, wash twice in PBS and resuspend the pellet in $198 \mu \mathrm{L}$ LS-TBS to an $\mathrm{OD}_{600}$ of 1.0 (see Note 13).

3. To label bacteria, add $2 \mu \mathrm{L}$ of the $500 \mu \mathrm{M}$ Syto82 solution to the bacterial culture in LS-TBS (total volume now $200 \mu \mathrm{L}$ ), vortex to ensure the dye is evenly resuspended in the LS-TBS and incubate for 30-45 minutes in the dark at room temperature. From this point onwards all steps must be performed in the dark to ensure that the Syto82 signal does not fade.

4. Following incubation, pellet the bacteria by centrifugation and resuspend the pellet thoroughly in LS-TBS.

5. Repeat Step 4 six more times for a total of seven washes. 
6. Resuspend the bacterial culture to a final optical density $\left(\mathrm{OD}_{600}\right)$ of 0.5 in $400 \mu \mathrm{L}$ LSTBST (see Note 14).

7. Add $70 \mu \mathrm{L}$ of the fluorescently labelled bacteria to each of the six subarrays on the Commented [A6]: Volume of OD 0.5 bacteria to add to slide? mucin microarray using an 8-well gasket slide and incubation cassette system (Agilent Technologies). Incubate bacteria on the slide for 1 hour at $37^{\circ} \mathrm{C}$ in the dark with gentle rotation (see Note 15). Incubate two subarrays with $70 \mu \mathrm{L}$ of different TRITC-labelled lectins for quality control (see Note 16).

8. Wash microarray slides five times in LS-TBST, once in LS-TBS and once in deionised water (see Note 17). Dry by centrifugation.

9. Scan slides using a microarray scanner that possesses a $532 \mathrm{~nm}$ laser. Syto 82 emits a green fluorescence at $560 \mathrm{~nm}$, so binding of fluorescently labelled bacteria is detected using the $532 \mathrm{~nm}$ laser (100\% laser power, 70\% photomultiplier tube [PMT] setting for both) (Molecular Devices). Data generated from scanned slides is extracted and exported to Excel as a text file, where subsequent data analysis is performed. The median feature intensity, with background subtracted, is used for each feature intensity value. The median of six replicate spots per subarray is used as a single data point.

\section{Notes}

1. Syto82 solution is supplied at a concentration of $5 \mathrm{mM}$. Make $500 \mu \mathrm{M}$ aliquots of the

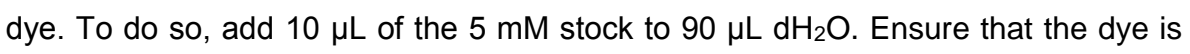
always stored at $-20^{\circ} \mathrm{C}$ and in the dark as it is light sensitive.

2. Once the TEMED and ammonium persulfate are added the gel will begin to polymerize so it is important to add these components last, quickly mix the solution using a pipette gun and pipette the solution into the cast.

3. Remove the isopropanol layer by rinsing with $\mathrm{dH}_{2} \mathrm{O}$ before adding the stacking gel.

4. Storing $1 \mathrm{X}$ transfer buffer at $4^{\circ} \mathrm{C}$ before use and placing the electroblotting tank on ice prevents the gel and membrane overheating during transfer.

5. Avoid touching the PVDF membrane with your gloves. Use a tweezers/forceps if necessary. Ensure the membrane is fully submerged in methanol and changes from white to translucent. 
6. N-Hydroxysuccinimide (NHS) esters of biotin are the most common type of biotinylation reagent. These come with varying spacer arm lengths to prevent steric hindrance of biotin when conjugated to target molecules with complex secondary structures such as mucin. We use a medium length spacer arm of $22.4 \AA$ for biotinylation of mucin.

7. To make whole cell lysates: Resuspend $C$. jejuni to an $\mathrm{OD}_{600}$ of 0.4 and pellet by centrifugation. Resuspend pellet in 2x SDS-PAGE reducing buffer and heat at $100^{\circ} \mathrm{C}$ for 10 minutes.

Transferring the gel at too high a voltage will cause the PVDF membrane to overheat. Stain the polyacrylamide gel following transfer in Coomassie Blue R250 to check for transfer efficiency.

8. As the blocking solution is incubated at $30^{\circ} \mathrm{C}$ overnight in gelatin, care must be taken in order to avoid any contamination of the solution. For this reason it is recommended that the container be sterilized and the gelatin heated to $37 \mathrm{oC}$ before use. Transfer the PVDF membrane from the blotter to the container in a laminar flow hood and cover with clingfilm to avoid contamination and minimize evaporation within the shaking incubator.

9. Following blocking, ensure the membrane is thoroughly washed to remove excess gelatin before incubating with mucin as the mucin can become gelatinized over time. Due to the small volume of purified mucin it may be necessary to dilute the sample in TBS in order to cover the membrane. Sealing the membrane and biotinylated mucin in a small plastic bag prevents evaporation of the sample and subsequent drying of the PVDF membrane.

10. Biotinylated mucin may be collected and frozen at $-20^{\circ} \mathrm{C}$ for reuse.

11. To reduce high background, wash the PVDF membrane overnight in TBST with a final wash in TBS or $\mathrm{dH}_{2} \mathrm{O}$ alone as Tween-20 can interfere with the ECL reagent.

12. When removing the membrane, take care to hold it at the corners and place it in the viewer, adding the ECL substrate promptly to prevent drying of the membrane. The ECL reagent becomes oxidized via the streptavidin peroxidase resulting in light emission that is detected by the gel-imaging viewer. 
13. The optimal OD for staining with Syto82 can vary depending on the bacteria. $C$. jejuni stains best at an $\mathrm{OD}_{600}$ of 1.0 . To obtain an $\mathrm{OD}_{600}$ of 1.0, spin down $1 \mathrm{~mL}$ of an $\mathrm{OD}_{600}$ of 0.2 and resuspend in $198 \mu \mathrm{L}$ of LS-TBS. The same amount of bacteria are present, but they have been concentrated five times, giving an $\mathrm{OD}_{600}$ of 1.0 in $200 \mu \mathrm{L}$ of LSTBS.

14. As the initial $200 \mu \mathrm{L}$ bacterial culture had an $O D_{600}$ of 1.0 , to obtain at a final $O D_{600}$ of 0.5 , resuspend the pellet for the final time in $400 \mu \mathrm{L}$ LS-TBST.

15. Incubating bacteria with the array:

i. Ensure that the gasket slide is clean and free of dirt/dust. Also check that the rubber ring around each compartment is not broken to ensure leakage doesn't occur. Place the gasket slide in the Agilent cassette.

ii. Take $70 \mu \mathrm{L}$ of the labelled bacterial culture and pipette into the appropriate compartment on the gasket slide.

iii. Take mucin array and make note of the number on the bottom to ensure that the correct array is analysed later. Incubate the array, with the numbered side facing down, with the bacterial culture on the gasket slide. Place the array slide onto the gasket slide at an angle to prevent air bubbles forming.

17. Fluorescently labelled lectins which bind to different glycan structures can be used as a quality control measure to ensure that the mucins are printed on each array. TRITClabelled lectins are commercially available (EY Laboratories, San Mateo, CA, USA). Generally, two different lectins that bind to different structures are included in each array. Dilute the lectin to the appropriate concentration in LS-TBST and add $70 \mu \mathrm{L}$ to a compartment on the gasket slide. Lectins are typically used at concentrations ranging from $5-15 \mu \mathrm{g} / \mathrm{mL}$. The optimal concentrations of suitable lectins to use are listed in reference (8).

18. Separate the array from the gasket slide in a beaker of LS-TBST to avoid cross contamination between subarrays. Add the array to a stainless steel slide rack and wash by dipping in and out of glass staining dishes filled with either LS-TBST, LSTBS or water. Leave the array in each dish for 30 seconds at a time.

\section{References}


1. Naughton JA, Mariño K, Dolan B et al., (2013) Divergent mechanisms of interaction of Helicobacter pylori and Campylobacter jejuni with mucus and mucins. Infect Immun 81(8):2838-50.

2. Tu QV, McGuckin MA, and Mendz GL (2008) Campylobacter jejuni response to human mucin MUC2: modulation of colonization and pathogenicity determinants. J Med Microbiol 57(Pt 7):795-802.

3. Alemka A, Whelan S, Gough R et al., (2010) Purified chicken intestinal mucin attenuates Campylobacter jejuni pathogenicity in vitro. J Med Microbiol 59(Pt 8): 898-903.

4. Byrne CM, Clyne M, and Bourke B (2007) Campylobacter jejuni adhere to and invade chicken intestinal epithelial cells in vitro. Microbiology 153(2):561-569.

5. McAuley JL, Linden SK, Png CW et al., (2007) MUC1 cell surface mucin is a critical element of the mucosal barrier to infection. J Clin Invest 117(8):2313-24.

6. Linden SK, Florin TH and McGuckin MA (2008) Mucin dynamics in intestinal bacterial infection. PLoS One 3(12):e3952. doi: 10.1371/journal.pone.0003952.

7. Dawson PA, Huxley S, Gardiner B et al., (2009). Reduced mucin sulfonation and impaired intestinal barrier function in the hyposulfataemic NaS1 null mouse. Gut 58(7):910-9.

8. Kilcoyne M, Gerlach JQ, Gough R et al., (2012) Construction of a natural mucin microarray and interrogation for biologically relevant glyco-epitopes. Anal Chem 84(7):3330-8.

\section{Figure Captions}

Figure 1. Mucin overlay of $C$. jejuni.

Whole cell lysate, cytosolic fraction (Cytosol), inner membrane fraction (IMP) and outer membrane fraction (OMP) showing the presence of a mucin binding ligand in the whole cell lysate and cytosolic fractions following electrophoretic transfer to a PVDF membrane from an SDS PAGE gel. 
